Çukurova Üniversitesi Mühendislik Mimarlık Fakültesi Dergisi, 30(2), 41-53 ss., Aralık 2015

Çukurova University Journal of the Faculty of Engineering and Architecture, 30(2), pp. 41-53, December 2015

\title{
Eğimli Açık Kanal Akımının Farklı Türbülans Modelleri ile Sayısal Modellemesi
}

\author{
Veysel GÜMÜß̧ ${ }^{* 1}$, Oğuz ŞiMŞSK ${ }^{2}$ \\ ${ }^{1}$ Harran Üniversitesi, Mühendislik Fakültesi, Inş̧aat Mühendisliği Bölümü, Şanlıurfa \\ ${ }^{2}$ Çukurova Üniversitesi, Mühendislik-Mimarlık. Fakültesi, İnşaat Mühendisliği Bölümü, Adana
}

Geliş tarihi:19.08.2015

Kabul tarihi:08.10.2015

\section{Özet}

Eğimli açık kanal akımının hız alanı, Lazer Doppler Anemometresi (LDA) ile ölçülmüş ve aynı deney koşullarındaki akımlar için, temel denklemler, sonlu hacimler yöntemine dayalı ANSYS-Fluent paket

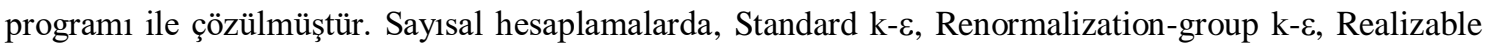
k- $\varepsilon$, Modifiye k- $\omega$ ve Shear Streess Transport türbülans kapatma modelleri kullanılmış, su yüzü profili VOF yöntemi ile hesaplanmışıtır. Sayısal modellerden elde edilen akım hızları ve su yüzü profilleri deneysel ölçümlerle karşılaştırılmıştır. Farklı türbülans modellerinin deneysel olarak doğrulanması amacıyla yapılan karşılaştırmalarda, Renormalization-group k- $\varepsilon$ türbülans modelinin, hız alanının hesaplanmasında ve su yüzünün belirlenmesinde, kullanılan modeller arasında en başarılı olduğu görülmüştür.

Anahtar kelimeler: Eğimli açık kanal akımı, Hız profili, Sayısal modelleme, Türbülans kapatma modelleri, VOF

\section{Numerical Modeling of Sloping Open Channel Flow Using Different Turbulence Closure Models}

\begin{abstract}
The velocity field of sloping open channel flow is measured using Laser Doppler Anemometry (LDA). Basic equations of the problem are solved by ANSYS-Fluent program package, using finite volume method, for the flow case having the same experimental conditions. In the numerical simulations, Standard k- $\varepsilon$, Renormalization-group k- $\varepsilon$, Realizable k- $\varepsilon$, Modified k- $\omega$ and Shear Stress Transport turbulence closure models are used, and the flow profile is computed using VOF method. Computational results for velocities and free surface profiles are compared with measured data. Experimental validations of the turbulence models show that, Realizable k- $\varepsilon$ turbulence model, among using the other turbulence models, is in general the most successful one in predicting the velocity field and free surface profiles of the present flow case.
\end{abstract}

Keywords: Sloping open channel flow, Velocity profile, Numerical modeling, Turbulence closure models, VOF

\footnotetext{
*Yazışmaların yapılacağı yazar: Veysel GÜMÜŞ, Harran Üniversitesi Mühendislik Fakültesi, İnşaat Mühendisliği Bölümü, Şanlıurfa, gumus@ harran.edu.tr
} 


\section{GíRiş̧}

Açık kanal akımları birçok çalışmaya konu olmuş ve hala incelemeye muhtaç bir konu olarak günümüzde popülerliğini korumaktadır. Açık kanal akımlarının araştırmalarında, akım alanın ve akım serbest su yüzü profilinin belirlenmesi önemli bir amaçtır. Hidrolik yapıların analizinde ve tasarımında, akım hız alanının ve su yüzünün belirlenmesi hem deneysel çalışmalarla hem de sayısal hesaplama yöntemlerinin kullanıldığı teorik modellemelerle yapilabilmektedir.

Teorik modelleme deneyleri fiziksel model deneylerine göre daha hızlı ve ekonomik olması nedeniyle, günümüzde bu tip su yapı etkileşimi problemlerinin çözümde oldukça sı kullanılmaktadır.

Teorik modellemelerde, akımı idare eden temel denklemlerin Hesaplamalı Akışkanlar Dinamiği (HAD) yöntemleri kullanılarak sayısal çözümü yapılarak, akımın serbest yüzeyi ile hız ve gerilme alanları ayrıntılı bir şekilde kısa süre içerisinde hesaplanabilmektedir. HAD yöntemleriyle türbülanslı akımların sayısal hesaplanmasında akımı idare eden denklemlerin çözülebilmesi için birçok araştırmacı tarafından türbülans kapatma modelleri geliştirilmiştir. Araştırmacılar tarafindan geliştirilen birçok türbülans modeli kullanılarak sayısal hesaplamalardan elde edilen teorik bulguların doğrulanması için, problemin fiziksel model bulguları ile karşılaştırılması gerekmektedir. Araştırmacılar tarafindan yapılan çalışmalara, yapı akım etkileşimi söz konusu olan problemlerde hangi türbülans modelinin, fiziksel model deney sonuçlarına daha yakın tahminde bulunduğunun belirlenmesi temel teşkil etmektedir [1-4].

Geçmişten günümüze, su ile yapı etkileşiminin mevcut olduğu türbülanslı akımların analizinde su yüzü profillerinin hesabında Akışkan Hacimleri (Volume of Fluid- VOF) yöntemi başarı ile kullanılmaktadır [5-11]. HAD uygulamalarında kullanılan türbülans modellerinin güvenilirliğini artırmak bakımından, türbülanslı akımların VOF yöntemine dayalı sayısal çözümlerinin deneylerle doğrulanmasına yönelik çalışmaların çeşitlendirilmesi ve çoğaltılmasına ihtiyaç vardır. Ayrıca, sayısal modellemelerde oluşturulan ağ yapısının çözümler üzerinde etkisinin olduğu bilinen bir gerçektir. Ağ yapısından bağımsız çözümün elde edilip edilmediğini belirlemek için ağ yakınsama indeksi (GCI-Grid Convergence Index) yöntemine birçok araştırmacı tarafindan başvurulmaktadır.

Bu çalışmada, eğimli dikdörtgen kesitli açık kanal akımın farklı kesitlerdeki hız profilleri tek boyutlu Lazer Doppler Anemometresi (LDA) ile ölçülmüştür. Deney akımları sonlu hacimler yöntemine dayalı ANSYS-Fluent paket programı kullanılarak sayısal olarak modellenmiş ve çözümü yapılmıştır. Türbülanslı akımın sayısal çözümünde, Standart $k-\varepsilon$, Renormalization Group k- $\varepsilon$, Realizable k- $\varepsilon$, Modifiye k- $\omega$ ve Shear Streess Transport türbülans modelleri kullanılmıştır. Kullanılan hesaplama ă̆ yapısının sayısal çözümler üzerindeki etkisini araştırmak için GCI yöntemi kullanılmıştır. Sayısal hesaplamalardan elde edilen çeşitli kesitlerdeki akım hız ve su yüzü profilleri, deneysel ölçümlerle karşılaştırılmış ve kullanılan türbülans modellerinin hız profillerinin tahminindeki başarısı araştırılmıştır.

\section{MATERYAL VE YÖNTEM}

\subsection{Deneyler}

Deneyler, Şekil 1'de şematik görünümü verilen, Harran Üniversitesi hidrolik laboratuvarında bulunan, uzunluğu $2,4 \mathrm{~m}$, genişliği ve derinliği 0,2 $\mathrm{m}$ olan, tüm yüzeyleri camdan yapılmış ve eğimi ayarlanabilir açık kanal modelinde yapılmıştır. Deneyler, akımın debisi $\mathrm{Q}=1,90 \mathrm{l} / \mathrm{s}$ ve kanal taban eğimi ise $2^{\circ}$ durumunda gerçekleştirilmiştir. Kanalın başlangıç noktasında, limnimetre ile ölçülen su derinliği $h_{0}=1,45 \mathrm{~cm}$, akım ortalama hız $V_{\mathrm{o}}=0,65 \mathrm{~m} / \mathrm{s}$ ve Froude sayıs $F r_{\mathrm{o}}=1,73$ olarak hesap edilmiştir. Akım hızlarının belirlenmesinde Dantec ${ }^{\circledR}$ LDA62N04 hı ölçme sistemi kullanılmıştır. Bu sistem, ölçüm bölgesine gönderilen iki lazer ışınının kesiştiği noktadan geçen parçacıklar yardımıyla, o noktadaki lazer 
1şınları düzlemindeki anlık akım hız bileşeninin belirli zaman aralıklarında ölçülmesini sağlamaktadır. Zaman serisi olarak kaydedilen hız değerlerinden, söz konusu noktaya ait zamansal ortalama akım hızı, türbülans hız sapınçları, türbülans şiddeti gibi çeşitli türbülans karakteristiklerinin belirlenmesi mümkün olmaktadır. Akımın su yüzü profili limnimetre kullanılarak ölçülmüştür.

\subsection{Temel Denklemler}

İncelenen açık kanal akımı düzenli, iki-boyutlu, sıkışmayan, türbülanslı bir serbest yüzeyli akımdır. Akımı idare eden temel denklemler, kütlenin korunumu ve momentumun korunumu (Reynoldsortalamalı Navier-Stokes) denklemleri aşağıdaki gibidir:

$$
\begin{aligned}
& \frac{\partial \bar{u}_{i}}{\partial x_{i}}=0 \\
& \rho\left(\frac{\partial \bar{u}_{i}}{\partial t}+\bar{u}_{j} \frac{\partial \bar{u}_{i}}{\partial x_{j}}\right)=\rho g_{i}-\frac{\partial \bar{p}}{\partial x_{i}}+\mu \frac{\partial^{2} \bar{u}_{i}}{\partial x_{j}^{2}}+\frac{\partial \tau_{i j}}{\partial x_{j}}
\end{aligned}
$$

(1) ve (2) denklemlerinde $u_{i}, \quad x_{i}$ doğrultusundaki hız bileșeni, $g$ yer çekimi ivmesi, $p$ basınç, $\mu$ dinamik viskozite, $\rho$ akışkan yoğunluğu ve $\tau_{i j}$ türbülans (Reynolds) gerilmeleridir.
$\mathrm{Bu}$ çalışmaya konu olan iki- boyutlu akımı idare eden yukarıdaki 3 adet denklem 6 adet bilinmeyen içermektedir, bunlar: iki hız bileşeni $\bar{u}_{i}$, basınç $\bar{p}$ ve üç bağımsız Reynolds gerilmesidir ( $\left.-\rho \overline{u_{i}^{\prime} u_{j}^{\prime}}\right)$. Böylece, denklem sisteminin çözülebilmesi için türbülans gerilmelerinin tanımlanmasına ihtiyaç duyulmaktadır. $\mathrm{Bu}$ sorun, yukarıdaki zamansalortalama denklemlerin sayısal çözümü sürecinde, denklemlerde yer alan türbülans gerilmelerinin uygun türbülans kapatma modelleriyle tanımlanmasını gerektirmektedir. Türbülans viskozitesinin doğrusal olarak ifade edilmesini esas alan Boussinesq yaklaşımına göre (2) denklemindeki türbülans kayma gerilmeleri bünye denklemi ile, sıkışmayan akımlar için aşağıdaki gibi verilmiştir:

$$
\tau_{i j}=-\rho \overline{u_{i}^{\prime} u_{j}^{\prime}}=\mu_{t}\left(\frac{\partial \bar{u}_{i}}{\partial x_{j}}+\frac{\partial \bar{u}_{j}}{\partial x_{i}}\right)-\frac{2}{3} \rho k \delta_{i j}
$$

burada $u_{i}^{\prime}$ ve $u_{j}^{\prime}$ yatay ve düşey türbülans hız sapınçları, $\mu_{t}$ türbülans viskozitesi, $k\left(=\overline{u_{i}^{\prime} u_{i}^{\prime}} / 2\right)$ türbülans kinetik enerjisi ve $\delta_{i j}$ Kronecker deltadır.

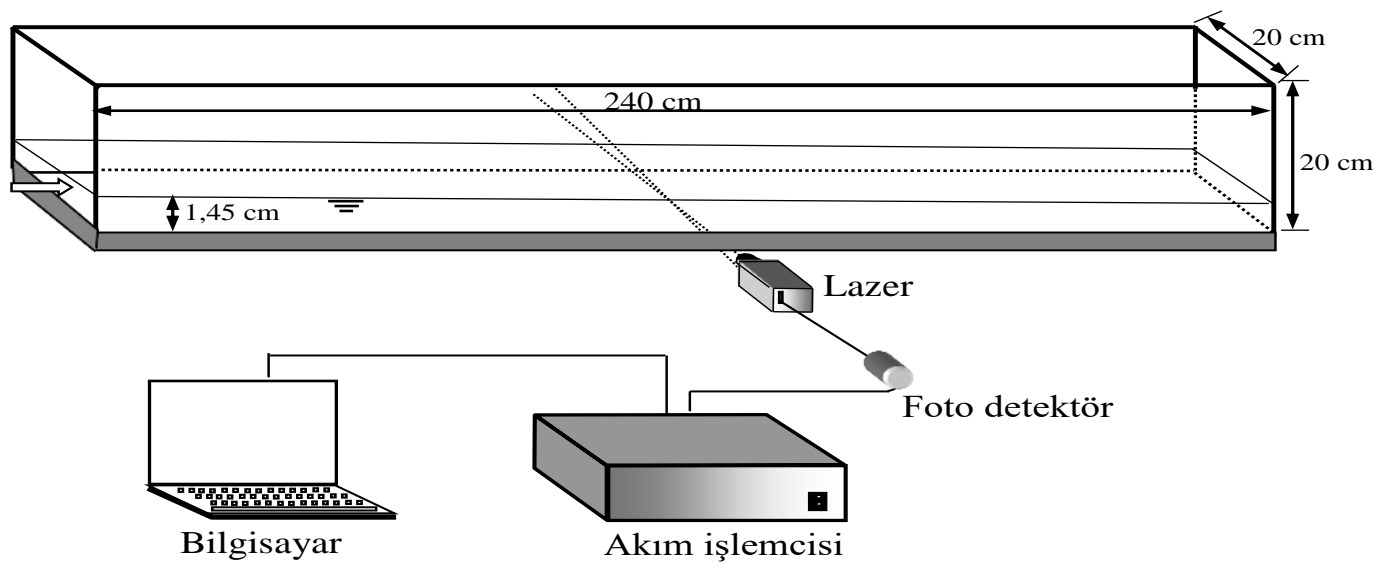

Şekil 1. Deney düzeneği 


\subsection{Türbülans Modelleri}

Denklem (3)'de görülen $\mu_{t}$ türbülans viskozitesinin hesaplanmasında bir çok türbülans kapatma modeli geliştirilmiştir. Bu çalışmada, $\mu_{t}$ 'nin hesabında, yaygın bir uygulama alanı olan, $k-\varepsilon$ tabanlı üç türbülans modeli ve $k-\omega$ tabanlı iki türbülans modeli kullanılmıştır:

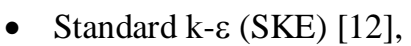

- Renormalization Group k-E (RNG) [13],

- Realizable k- $\varepsilon$ (RKE) [14],

- Modifiye k- $\omega$ (MKW) [15],

- Shear Strees Transport (SST) [16],

bu modeller aşağıda kısaca açıklanmıştır.

\subsubsection{SKE Türbülans Modeli}

$$
\mu_{t}=\rho C_{\mu} \frac{k^{2}}{\varepsilon}
$$

$$
\begin{aligned}
\frac{\partial(\rho \varepsilon)}{\partial t}+\bar{u}_{j} \frac{\partial(\rho \varepsilon)}{\partial x_{j}} & =\frac{\partial}{\partial x_{j}}\left[\left(\mu+\frac{\mu_{t}}{\sigma_{\varepsilon}}\right) \frac{\partial \varepsilon}{\partial x_{j}}\right] \\
& +C_{1 \varepsilon} \frac{\varepsilon}{k} \tau_{i j} \frac{\partial \bar{u}_{i}}{\partial x_{j}}-C_{2 \varepsilon} \rho \frac{\varepsilon^{2}}{k}
\end{aligned}
$$

SKE model sabitleri, $C_{\mu}=0,09, \sigma_{k}=1,0, \sigma_{\varepsilon}=1,3$, $C_{1 \varepsilon}=1,44, C_{2 \varepsilon}=1,92$ değerlerini almaktadır [12].

\subsubsection{RNG Türbülans Modeli}

$\mathrm{Bu}$ modelde $k$-denklemi SKE ile ayn olup $\varepsilon$-denklemi aşă̆ıdaki gibi ilave kaynak terimi içermektedir:

$$
\begin{aligned}
\frac{\partial(\rho \varepsilon)}{\partial t}+\bar{u}_{j} \frac{\partial(\rho \varepsilon)}{\partial x_{j}} & =\frac{\partial}{\partial x_{j}}\left[\left(\mu+\frac{\mu_{t}}{\sigma_{\varepsilon}}\right) \frac{\partial \varepsilon}{\partial x_{j}}\right] \\
& +C_{1 \varepsilon}^{*} \frac{\varepsilon}{k} \tau_{i j} \frac{\partial \bar{u}_{i}}{\partial x_{j}}-C_{2 \varepsilon} \rho \frac{\varepsilon^{2}}{k}
\end{aligned}
$$

Model sabitleri aşağıdaki gibi verilmiştir:
$C_{\mu}=0,0845, \quad \sigma_{k}=\sigma_{\varepsilon}=0,7194$,

$C_{1 \varepsilon}^{*}=C_{1 \varepsilon}-\frac{\eta\left(1-\eta / \eta_{0}\right)}{1+\beta \eta^{3}}, \quad C_{2 \varepsilon}=1,68$,

$C_{1 \varepsilon}=1,42, \eta=\left(2 S_{i j} S_{i j}\right)^{1 / 2} \frac{k}{\varepsilon}$,

$S_{i j}=\frac{1}{2}\left(\bar{u}_{i, j}+\bar{u}_{j, i}\right), \quad \eta_{0}=4,377, \quad \beta=0,012$

(Deneysel)

$S_{i j}$ şekil değiştirme hızı tansörüdür. Görüldüğü gibi (7) denklemi akışkan şekil değiştirmesine bağlı $\eta$ parametresini içermektedir. $\mathrm{Bu}$ ilave parametre sayesinde RNG modelinin ivmelenen, şiddetli eğriselliğe maruz, sınır tabakasının ayrıldığı, ikincil akımlar ve durma noktasının mevcut olduğu akımlarda SKE modeline göre daha gerçekçi sonuçlar verdiği iddia edilmiştir [13].

\subsubsection{RKE Türbülans Modeli}

Akım alanındaki yüksek şekil değiştirme hızlarının ve sınır tabakası ayrılmasının mevcut olduğu karmaşık akım durumlarında SKE türbülans modeli üzerinde, performans artırıcı olarak RKE modeli adı altında şu iyileştirmeler yapılmıştır: (a) türbülans viskozitesi, $\mu_{t}$, ifadesinde, sabit bir değer yerine değişken $C_{\mu}$ terimi kullanılarak SKE modelindeki katı yüzeye dik şekil değiştirme bileşenlerinin değeri küçültülmüş, ve (b) $\varepsilon$ transport denkleminde yerel şekil değiştirme hızını esas alan farklı bir kaynak terimi kullanılmıştır. Shih ve ark. [14] $C_{\mu}^{*}$ için aşağıdaki formülü vermişlerdir:

$$
C_{\mu}^{*}=\frac{1}{A_{o}+A_{s} \frac{U^{*} k}{\varepsilon}}
$$

Burada, $A_{o}=4, A_{s}=\sqrt{6} \cos \phi$,

$\phi=\frac{1}{3} \arccos (\sqrt{6} W), W=\frac{S_{i j} S_{j k} S_{k i}}{\tilde{S}^{3}}, \tilde{S}=\sqrt{S_{i j} S_{i j}}$, 
$U^{*}=\sqrt{S_{i j} S_{i j}+\tilde{\Omega}_{i j} \tilde{\Omega}_{i j}}, \tilde{\Omega}_{i j}=\Omega_{i j}-2 \varepsilon_{i j k} \omega_{k}^{*}$,

$\Omega_{i j}=\bar{\Omega}_{i j}-\varepsilon_{i j k} \omega_{k}^{*}, \Omega_{i j}=\frac{1}{2}\left(\bar{u}_{i, j}-\bar{u}_{j, i}\right)$

$\bar{\Omega}_{i j}, \omega_{k}^{*}$ açısal hızı ile dönen eksen takımına göre ölçülen ortalama rotasyon hızı tansörüdür. $\varepsilon$-denklemi aşağıdaki gibi ifade edilmiştir:

$$
\begin{aligned}
\frac{\partial}{\partial \mathrm{t}}(\rho \varepsilon)+\bar{u}_{j} \frac{\partial(\rho \varepsilon}{\partial x_{\mathrm{j}}} & =\frac{\partial}{\partial x_{\mathrm{j}}}\left[\left(\mu+\frac{\mu_{t}}{\sigma_{\varepsilon}}\right) \frac{\partial \varepsilon}{\partial x_{\mathrm{j}}}\right] \\
& +\rho C_{1} S \varepsilon-\rho C_{2} \frac{\varepsilon^{2}}{k+\sqrt{v \varepsilon}}
\end{aligned}
$$

Model sabitleri aşağıdaki gibi önerilmiştir:

$$
\begin{aligned}
& C_{1}=\max \left[0,43, \frac{\eta}{\eta+5}\right], \eta=S \frac{k}{\varepsilon}, S=\sqrt{S_{i j} S_{i j}}, \\
& C_{2}=1,9, \sigma_{k}=1,0, \sigma_{\varepsilon}=1,2
\end{aligned}
$$

RKE modeli de RNG gibi, ivmelenen, eğrisel, sınır tabakasının ayrıldığı, ikincil akımların var olduğu akımlarda SKE modeline göre daha başarılı olduğu ifade edilmiştir [14].

\subsubsection{MKW Türbülans Modeli}

Wilcox, kendisine ait Standard $k-\omega$ (SKW) modelini [14] modifiye ederek aşağıdaki Modifiye $k-\omega$ (MKW) modelini [12] vermiştir. MKW modelinde, düşük-Reynolds-sayısı düzeltmelerini de göz önüne almak üzere, türbülans viskozitesine bir sönüm fonksiyonu eklenmiştir. İkinci transport denklemi olarak $\varepsilon$ yerine türbülans kinetik enerjisinin özgül kayıp oran1, $\omega=\varepsilon / \mathrm{k}$, kullanılmıştır. Bu model ile türbülans viskozitesi $\mu_{t}$, k-denklemi ve $\omega$-denklemi aşağıdaki gibi ifade edilmektedir.

$\mu_{\mathrm{t}}=\alpha^{*} \frac{\rho k}{\omega}$

Burada, $\alpha^{*}$ düşük Reynolds sayısı düzeltmesi için sönüm fonksiyonudur. $k$ ve $\omega$ denklemleri aşağıdaki gibi ifade edilir:

$$
\begin{aligned}
\frac{\partial}{\partial \mathrm{t}}(\rho k)+\frac{\partial}{\partial x_{\mathrm{j}}}\left(\rho k u_{i}\right)= & \frac{\partial}{\partial x_{\mathrm{j}}}\left[\left(\mu+\frac{\mu_{t}}{\sigma_{k}}\right) \frac{\partial k}{\partial x_{\mathrm{j}}}\right] \\
& +\tau_{i j} \frac{\partial \bar{u}_{i}}{\partial x_{\mathrm{j}}}-\beta^{*} \rho k \omega \\
\frac{\partial}{\partial \mathrm{t}}(\rho \omega)+\frac{\partial}{\partial x_{\mathrm{j}}}\left(\rho k u_{i}\right)= & \frac{\partial}{\partial x_{\mathrm{j}}}\left[\left(\mu+\frac{\mu_{t}}{\sigma_{\omega}}\right) \frac{\partial \omega}{\partial x_{\mathrm{j}}}\right] \\
& +\alpha \frac{\omega}{k} \tau_{i j} \frac{\partial \bar{u}_{i}}{\partial x_{\mathrm{j}}}-\beta \rho \omega^{2}
\end{aligned}
$$

Model sabitleri ve yardımcı eşitlikler (sıkışmayan akım için) aşağıdaki gibi verilmiştir:

$$
\begin{aligned}
& \alpha^{*}=\frac{\alpha_{\mathrm{o}}^{*}+\mathrm{Re}_{\mathrm{t}} / \mathrm{R}_{\mathrm{k}}}{1+\mathrm{Re}_{\mathrm{t}} / \mathrm{R}_{\mathrm{k}}}, \quad \alpha_{\mathrm{o}}^{*}=\frac{\beta_{\mathrm{o}}}{3}, \quad \beta_{\mathrm{o}}=0,072, \\
& \mathrm{R}_{\mathrm{k}}=6, \quad \mathrm{Re}_{\mathrm{t}}=\frac{\rho \mathrm{k}}{\mu \omega}, \quad \alpha=\frac{0,52}{\alpha^{*}} \frac{\alpha_{\mathrm{o}}+\mathrm{Re}_{\mathrm{t}} / \mathrm{R}_{\omega}}{1+\mathrm{Re}_{\mathrm{t}} / \mathrm{R}_{\omega}}, \\
& \alpha_{\mathrm{o}}=\frac{1}{9}, \quad \sigma_{\mathrm{k}}=2, \mathrm{R}_{\omega}=2,95, \quad \sigma_{\mathrm{o}}^{*}=\frac{9}{100} \frac{4 / 15+\left(\mathrm{Re}_{\mathrm{t}} / \mathrm{R}_{\beta}\right)^{4}}{1+\left(\mathrm{Re}_{\mathrm{t}} / \mathrm{R}_{\beta}\right)^{4}}, \\
& \beta^{*}=\beta_{\mathrm{o}}^{*} \mathrm{f}_{\beta^{*}} \quad, \quad
\end{aligned}
$$

$\mathrm{R}_{\beta}=8, \quad \mathrm{f}_{\beta^{*}}=\left\{\begin{array}{ll}1, & \chi_{\mathrm{k}} \leq 0 \\ \frac{1+680 \chi_{\mathrm{k}}^{2}}{1+400 \chi_{\mathrm{k}}^{2}}, & \chi_{\mathrm{k}}>0\end{array} \quad \beta=\beta_{\mathrm{o}} \mathrm{f}_{\beta}\right.$,

$\mathrm{f}_{\beta}=\frac{1+70 \chi_{\omega}}{1+80 \chi_{\omega}}$

$$
\begin{aligned}
& \chi_{\omega} \equiv\left|\frac{\Omega_{\mathrm{ij}} \Omega_{\mathrm{jk}} \mathrm{S}_{\mathrm{ki}}}{\left(\beta_{\mathrm{o}}^{*} \omega\right)^{3}}\right|, \chi_{\mathrm{k}} \equiv \frac{1}{\omega^{3}} \frac{\partial \mathrm{k}}{\partial \mathrm{x}_{\mathrm{j}}} \frac{\partial \omega}{\partial \mathrm{x}_{\mathrm{j}}}, \\
& \Omega_{\mathrm{ij}}=\frac{1}{2}\left(\partial \overline{\mathrm{u}}_{\mathrm{i}, \mathrm{j}}-\partial \overline{\mathrm{u}}_{\mathrm{j}, \mathrm{i}}\right)
\end{aligned}
$$

MKW modelinin yüksek-Reynolds-sayısı formunda $\alpha^{*=1}, \beta_{0}^{*}=9 / 100$ olarak alınır. MKW modelinin, katı ile sınırlandırılmış ya da serbest türbülanslı akımların analizinde, sınır tabakalarının 
logaritmik hız bölgesinde, pozitif basınç gradyanının olduğu ayrılma bölgelerinde, SKE modeline göre üstünlük sağladığı ifade edilmiştir [12].

\subsubsection{SST Türbülans Modeli}

SST modeli, katı sınıra yakın akım bölgelerinde $k$ $\omega$ [12], uzak bölgelerde ise standart $k-\varepsilon$ türbülans modelinin daha uygun olduğu varsayımından hareketle her iki modelin üstünlüklerini tek modelde birleştiren bir türbülans modelidir. $\mathrm{Bu}$ model, bir karışım fonksiyonu yardımı ile modelin katsayılarını, geçerli olduğu varsayılan bölgeler itibariyle $k-\omega$ ve $k-\varepsilon$ model katsayılarına uyarlayarak, katı sınıra yakın yerlerde (türbülanslı iç bölgede) $k$ - $\omega$ modeli ile uyum sağlarken, katı sınırdan uzaklaştıkça (türbülanslı dış bölgede) yumuşak bir geçişle $k$ - $\varepsilon$ türbülans modeline yaklaşmaktadır [13]. $F_{1}$ karışım fonksiyonu olarak SST modelindeki taşınım denklemleri aşağıdaki gibi verilmiştir:

$$
\begin{aligned}
\frac{\partial(\rho k)}{\partial t}+\bar{u}_{j} \frac{\partial(\rho k)}{\partial x_{j}}= & \frac{\partial}{\partial x_{j}}\left[\left(\mu+\sigma_{k} \mu_{t}\right) \frac{\partial k}{\partial x_{j}}\right] \\
& +\tau_{i j} \frac{\partial \bar{u}_{i}}{\partial x_{j}}-\beta^{*} \rho \omega k \\
\frac{\partial(\rho \omega)}{\partial t}+\bar{u}_{j} \frac{\partial(\rho \omega)}{\partial x_{j}}= & \frac{\partial}{\partial x_{j}}\left[\left(\mu+\sigma_{\omega} \mu_{t}\right) \frac{\partial \omega}{\partial x_{j}}\right] \\
& +\frac{\gamma}{v_{t}} \tau_{i j} \frac{\partial \bar{u}_{i}}{\partial x_{j}}-\beta \rho \omega^{2} \\
& +2\left(1-F_{1}\right) \rho \sigma_{\omega 2} \frac{1}{\omega} \frac{\partial k}{\partial x_{j}} \frac{\partial \omega}{\partial x_{j}}
\end{aligned}
$$

$\omega(=\varepsilon / k)$ türbülans kinetik enerjisi özgül kayıp oranıdır. $\mathrm{Bu}$ modeldeki farklı sabitler, orijinal $k-\omega$ $\left(\phi_{1}\right)$ ve dönüştürülmüş $k-\varepsilon\left(\phi_{2}\right)$ model katsayılarının interpolasyonu ile aşağıdaki gibi ifade edilir:
$\phi=F_{1} \phi_{1}+\left(1-F_{1}\right) \phi_{2}$, örneğin:

$\sigma_{k}=F_{1} \sigma_{k 1}+\left(1-F_{1}\right) \sigma_{k 2}$ ve

$\sigma_{\omega}=F_{1} \sigma_{\omega 1}+\left(1-F_{1}\right) \sigma_{\omega 2}$

$k$ - $\omega$ için $\phi_{1}$ sabitleri: $\sigma_{k 1}=0,85, \sigma_{\omega 1}=0,5$,

$\beta_{1}=0,075 \beta^{*}=0,09, \gamma_{1}=\frac{\beta_{1}}{\beta^{*}}-\frac{\sigma_{\omega 1} \kappa^{2}}{\sqrt{\beta^{*}}}$,

$\kappa=0,41$

$k-\varepsilon$ için $\phi_{2}$ sabitleri: $\sigma_{k 2}=1,0, \quad \sigma_{\omega 2}=0,856$,

$\beta_{2}=0,0828, \beta^{*}=0,09, \gamma_{2}=\frac{\beta_{2}}{\beta^{*}}-\frac{\sigma_{\omega 2} \kappa^{2}}{\sqrt{\beta^{*}}}$

$\kappa=0,41$ ve ifadeler içerisinde bulunan $F_{1}$ fonksiyonu aşağıdaki gibidir:

$$
\begin{aligned}
& F_{1}=\tanh \left\{\min \left[\operatorname{mak}\left(\frac{\sqrt{k}}{0.09 \omega y} ; \frac{500 v}{y^{2} \omega}\right) ; \frac{4 \rho \sigma_{\omega 2} k}{C D_{k \omega} y^{2}}\right]\right\}^{4}, \\
& C D_{k \omega}=\operatorname{mak}\left(2 \rho \sigma_{\omega 2} \frac{1}{\omega} \frac{\partial k}{\partial x_{j}} \frac{\partial \omega}{\partial x_{j}} ; 10^{-20}\right)
\end{aligned}
$$

$y$ en yakın duvar uzaklığını göstermektedir.

Türbülans kayma gerilmesindeki taşınım etkisini göz önüne almak üzere türbülans viskozitesi aşağıdaki gibi modifiye edilmiştir [13]. $k-\omega$ modelinin, yapılan bu değişiklik ile pozitif basınç gradyanına sahip sınır tabakası akımlarının analizinde ve sinır tabakası ayrilma yerinin belirlenmesinde SKE türbülans modeline göre daha başarılı olduğu görülmüştür. Bradshaw hipotezine dayanarak, bir sınır tabakası içindeki kayma gerilmesi aşağıdaki gibi ifade edilmektedir:

$$
\tau=\rho a_{1} k
$$

Burada sabit değer $a_{1}=0,31$ 'dir. (15) denkleminin sağlanması için türbülans viskozitesi yeniden tanımlanırsa: 


$$
\begin{aligned}
v_{t} & =\frac{a_{1} k}{\operatorname{mak}\left(a_{1} \omega ; \zeta F_{2}\right)}, \\
F_{2} & =\tanh \left[\operatorname{mak}\left(2 \frac{\sqrt{k}}{0,09 \omega y} ; \frac{500 v}{y^{2} \omega}\right)\right]
\end{aligned}
$$

Ortalama vortisitenin mutlak değeri, $\zeta=|\partial \bar{u} / \partial y|$ olup, $F_{2}$ fonksiyonu sınır tabakası akımı için 1, serbest türbülanslı kayma tabakaları için 0 değerini almaktadır.

\subsection{Akıșkan Hacimleri Yöntemi (VOF)}

Bu çalışmada, su-hava ara yüzünün hesabında akışkan hacimleri (Volume of Fluid-VOF) yöntemi kullanılmıştır [17]. VOF yöntemi, esas olarak hesaplama ağındaki eleman hacimlerinin boş, kısmen dolu ya da tamamen su ile dolu olduğunu belirlemektedir. A $\breve{g}$ elemanlarının hacimsel doluluk oranını temsilen, $F=1$ için ağ elemanı tam dolu, $F=0$ için boş (hava ile dolu) ve $0>F>1$ için su ile kısmen dolu olmaktadır (Şekil 2).

Akışkan Hacimleri Yöntemi ile serbest su yüzünün hesaplanmasında "Geo-Reconstruct" yaklaşımı kullanılmıştır [18]. Bu yaklaşıma göre, öncelikle, kısmen dolu her bir hücrenin, doluluk oranı ve onun türevleri ile ilgili bilgilere dayanılarak, havasu doğrusal ara yüzünün hücre ağırlık merkezine göre yeri belirlenir.

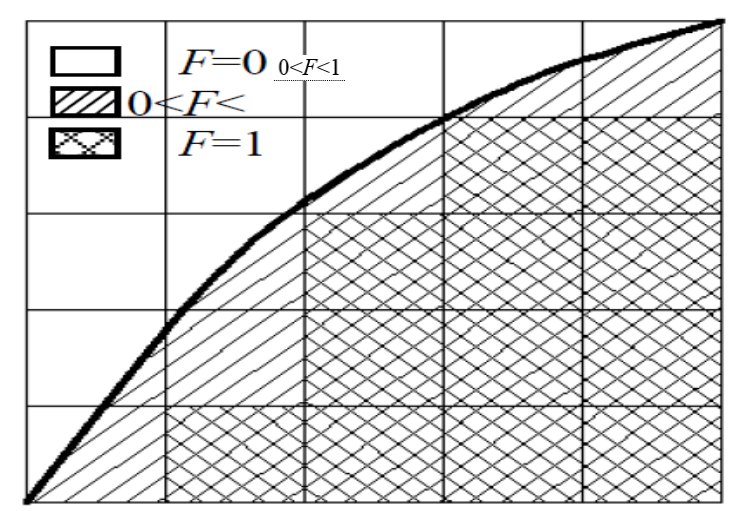

Şekil 2. Ağ elemanlarının doluluk oranı
Bir sonraki adımda, hesaplanmış doğrusal ara yüzün yeri ve eleman yüzeylerinde hesaplanmış normal ve teğetsel hız bilgileri kullanılarak her bir eleman yüzeyinden taşınan akışkan miktarları hesaplanır. Son olarak, bir önceki adımda hesaplanan akışkan miktarları göz önüne alınarak, süreklilik denklemi ile her bir hücrenin hacimsel doluluk oranı belirlenir.

\section{5. Çözüm Bölgesinin Sınır Şartları}

Eğimli açık kanal akımının sayısal modellenmesi için kullanılan çözüm bölgesi ve sınır şartların Şekil 3'te verilmiştir. $x, y$ koordinat sisteminin orijini, çözüm bölgesinin sol alt köşesinde alınmış, sınır şartları olarak çözüm bölgesinin üst ve çıkış sinırlarında $p=0$, kanal tabanında sifir hız, yani $u=0, v=0$ olarak tanımlanmıştır. Giriş sınır şartı olarak, deneysel ölçümlerden elde edilen hız profili yatay hız bileşeni $u=u$ (y) olarak tanımlanırken, düşey hız bileşeni $v=0$ olarak alınmıştır.

Zamana bağlı çözüm sürecinde, başlangiç şartı olarak, $t=0$ anında boş olan çözüm bölgesinin giriş sınırında VOF yöntemi için $F=1$ alınmış ve sayısal modellemede kullanılan tüm türbülans modelleri için zaman adımı $\Delta t=0.001 \mathrm{~s}$ olarak seçilmiş ve sayısal çözümün kararlı hale geldiği 30 s kadar çözüm yapılmıştır. SKE, RNG ve RKE modellerinde, kanal tabanında katı sınıra yakın akım bölgesinin modellenmesinde Chen ve Patel [19] tarafından önerilen iki-tabakalı çözümü esas alan ve genişletilmiş iki-tabakalı duvar-yakını modellemesi olarak anılan yöntem kullanılmıştır. (1) ve (2) temel denklemlerinin, Şekil 3 'te görülen sınır şartlarına göre $\bar{u}, \bar{v}$ ve $\bar{p}$ için sayısal çözümü, sonlu hacimler yöntemine dayalı ANSYS-Fluent $^{\circledR} \quad$ v.12.1 paket programı kullanılarak yapılmıştır.

\subsection{Hesaplama Ăğının Tasarımı}

Hesaplama ağının tasarımı için çözüm bölgesi, dört alt bölgeye ayrılmış ve ağ yapısının çözüm üzerindeki etkisinin incelenmesinde kullanılan 


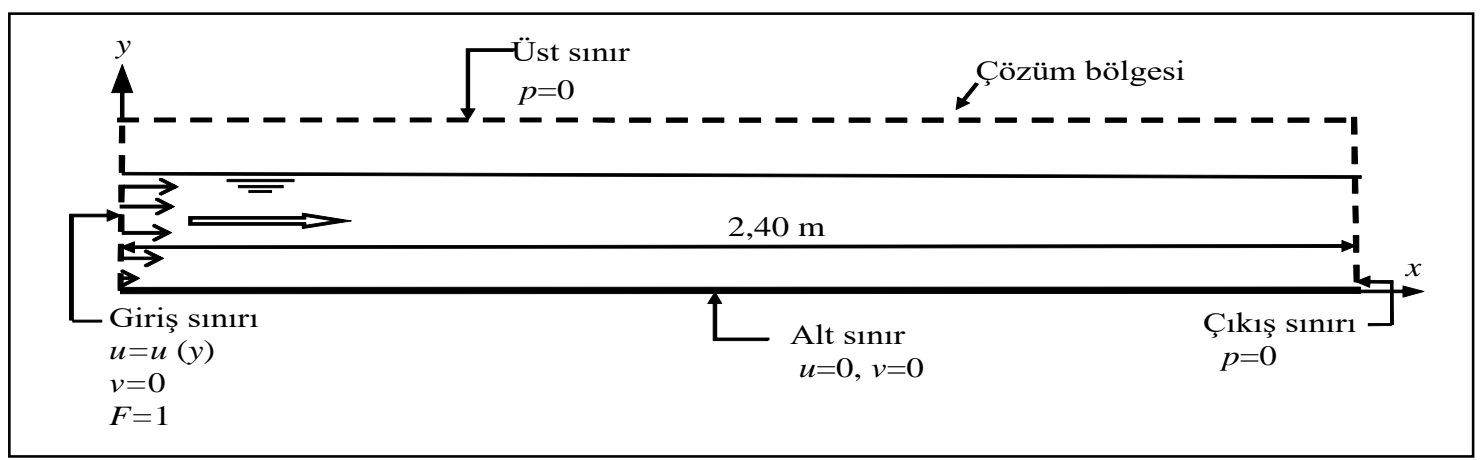

Şekil 3. Sayısal çözüm bölgesi ve sınır şartları

ayrıklaştırma hatasının tespiti için üçlü bir hesaplama ağı oluşturulmuştur. Hesaplama ağının her bir bölgesindeki eleman sayısı yaklaşık olarak $\% 50$ ve $\% 100$ oranında artırılmak suretiyle dörtgen elemanlardan oluşan üç farklı yoğunluğa sahip, A $\breve{1} 1, \quad A \breve{g} 2$ ve A $\breve{g} 3$, hesaplama ağlar1 oluşturulmuştur. Çizelge 1'de, sayısal hesaplamalarda kullanılan üç farklı ağ yapısı için eleman sayıları verilmiş̧ir, burada ilk değer düşey eleman sayısını, ikinci değer ise yatay eleman sayısını ifade etmektedir. Sayısal çözüm alanındaki ağ yapısının yeterli sıklıkta olup olmadığı, bir başka ifadeyle ă̆ yapısından bağımsız sayısal çözümler elde etmek amaciyla ele alınan üçlü ağ sisteminde yapılan sıklaştırmanın uygunluğu, GCI (Grid Convergence Index-A ̆ Yakınsama İndeksi) yöntemiyle test edilmiştir [20, 21]. Ağ3 sistemiyle, akım hızlarındaki hataların kabul edilebilir bir sınır olan \%2'den küçük olduğu görülmüş ve hesaplama hassasiyetinin ağ yoğunluğundan bağımsızlaştığı kanaatine varılmıştır.

Çizelge 1. Farklı yoğunluktaki hesaplama ağlarının elaman sayıları

\begin{tabular}{|c|c|c|}
\hline A $\breve{g} 1-$ Kaba & A $\breve{g} 2-$ Orta & A $\breve{g} 3$-̇̇nce \\
\hline $15 \times 150$ & $20 \times 200$ & $30 \times 300$ \\
\hline
\end{tabular}

\section{BULGULAR ve TARTIŞMA}

\subsection{Deneysel ve Hesaplanan Hiz Profilleri}

$\mathrm{Bu}$ çalışmada kullanılan türbülans kapatma modellerinin doğrulanması bağlamında, deneysel ve sayısal hesap bulgularının niceliksel olarak karşılaştırılmasında, hız ve su yüzü profilleri için hesaplanan Ortalama Karesel Hata $(\mathrm{OKH})$ ve Ortalama Mutlak Göreceli Hata (OMGH) değerleri ölçüt olarak alınmıştır:

$\mathrm{OKH}=\frac{1}{N} \sum_{n=1}^{N}\left(v_{d}-v_{h}\right)^{2}$

$\mathrm{OMGH}=\frac{1}{N} \sum_{n=1}^{N}\left|\frac{v_{d}-v_{h}}{v_{d}}\right| x 100$

Burada, $v_{d}$ vev $v_{h}$ sirasiyla deneysel ve hesaplanan hız değerlerini, $N$ işlem yapılan hız profilinde ele alınan nokta sayısını göstermektedir.

Çizelge 2'de, bu çalışmada kullanılan türbülans modelleriyle akım farklı kesitlerinde hesaplanan hız profilleri için $\mathrm{OKH}$ ve $\mathrm{OMGH}$ değerleri verilmiştir. Çizelgenin son satırında, tüm kesitler itibariyle ortalama $\mathrm{OKH}$ ve $\mathrm{OMGH}$ değerleri verilmiştir. Tablolarda verilen ortalama $\mathrm{OKH}$ ve OMGH değerlerine göre, tüm çözüm bölgesini kapsayacak şekilde, kullanılan türbülans modellerinin başarı sıralaması RNG, RKE, SKE, SST ve MKW şeklinde olduğu görülmektedir. $k$ ve $e$ denklemlerini çözen SKE, RKE ve RNG türbülans modelleri $k$ ve $w$ denklemlerini çözen MKW ve SST türbülans modellerine göre deneysel sonuçlara daha yakın tahminde bulunmuştur. Kanal başlangıç bölgelerinde ( $x=20,40,60$ ve 75$)$ SKE türbülans modeli RNG modeline göre daha 
Çizelge 2. Farklı türbülans modelleri ile hesaplanan hız profilleri için $\mathrm{OKH}\left(\mathrm{mm}^{2} / \mathrm{s}^{2}\right)$ ve $\mathrm{OMGH}(\%)$ değerleri

\begin{tabular}{|c|c|c|c|c|c|c|c|c|c|c|}
\hline \multirow{2}{*}{$\begin{array}{c}\boldsymbol{x} \\
(\mathbf{c m})\end{array}$} & \multicolumn{2}{|c|}{ SKE } & \multicolumn{2}{c|}{ RKE } & \multicolumn{2}{c|}{ RNG } & \multicolumn{2}{c|}{ MKW } & \multicolumn{2}{c|}{ SST } \\
\hline & $\mathbf{O K H}$ & $\mathbf{O M G H}$ & OKH & OMGH & OKH & OMGH & OKH & OMGH & OKH & OMGH \\
\hline $\mathbf{2 0}$ & 4,853 & 2,784 & 6,051 & 2,845 & 8,455 & 3,056 & 8,498 & 3,323 & 5,798 & 2,875 \\
\hline $\mathbf{4 0}$ & 4,380 & 1,969 & 3,627 & 2,119 & 4,897 & 2,333 & 11,279 & 4,230 & 8,196 & 3,724 \\
\hline $\mathbf{6 0}$ & 11,727 & 3,099 & 9,242 & 3,361 & 10,770 & 3,525 & 25,257 & 5,855 & 20,940 & 5,311 \\
\hline $\mathbf{7 5}$ & 6,302 & 2,461 & 6,505 & 2,668 & 6,638 & 2,708 & 28,014 & 5,665 & 19,428 & 4,744 \\
\hline $\mathbf{9 0}$ & 11,463 & 3,600 & 12,543 & 3,475 & 11,327 & 3,347 & 14,283 & 4,610 & 12,362 & 4,218 \\
\hline $\mathbf{1 0 5}$ & 11,792 & 4,563 & 13,606 & 4,745 & 12,859 & 4,672 & 35,564 & 7,326 & 28,419 & 6,972 \\
\hline $\mathbf{1 2 0}$ & 6,015 & 2,665 & 7,224 & 2,858 & 6,258 & 2,844 & 27,222 & 6,153 & 22,924 & 5,676 \\
\hline $\mathbf{1 4 0}$ & 8,063 & 3,456 & 6,756 & 3,124 & 7,624 & 3,151 & 18,521 & 5,298 & 13,916 & 4,583 \\
\hline $\mathbf{1 6 0}$ & 9,581 & 3,093 & 10,497 & 3,186 & 7,843 & 2,866 & 29,896 & 6,123 & 21,380 & 5,358 \\
\hline $\mathbf{1 8 0}$ & 4,851 & 2,130 & 5,273 & 1,952 & 3,189 & 1,620 & 23,651 & 5,116 & 12,669 & 3,998 \\
\hline $\mathbf{2 0 0}$ & 6,704 & 2,621 & 6,278 & 2,341 & 4,449 & 2,063 & 22,922 & 4,687 & 10,797 & 3,537 \\
\hline $\mathbf{2 2 0}$ & 7,886 & 2,716 & 6,346 & 2,424 & 4,412 & 2,147 & 17,127 & 3,877 & 10,190 & 2,837 \\
\hline Ort. & 7,801 & 2,930 & 7,829 & 2,925 & $\mathbf{7 , 3 9 3}$ & $\mathbf{2 , 8 6 1}$ & 21,853 & 5,189 & 15,585 & 4,486 \\
\hline
\end{tabular}

deneysel ölçümlere daha fazla yakınsamıştır. Kanal ortası ve bitiş bölgesinde RNG modeli diğer modellere bariz bir üstünlük sağlamıştır. $\mathrm{Bu}$ sonuçlardan, mevcut problemde hız alanının simülasyonu bakımından en küçük $\mathrm{OKH}$ ve $\mathrm{OMGH}$ değerine sahip olan $\mathrm{RNG}$ modelinin kullanılan türbülans modelleri arasında en başarılı türbülans modeli olduğu görülmektedir.

Kanalın farklı kesitlerinde ölçülen, kanal genelinde hesaplanan ortalama $\mathrm{OKH}$ ve OMGH hata değerlerine göre en başarılı model olan RNG türbülans modeli kullanılarak elde edilen sayısal hız profilleri, yatay eksen $u_{\text {mak }}$ düşey eksen $y_{\text {mak }}$ değerine bölünerek boyutsuz olarak Şekil 4'te verilmiştir. Bu grafiklerden, $x=20,40,60$ ve $75 \mathrm{~cm}$ kesitlerinde katı sınıra yakın bölgede, deneysel ve sayısal bulguların birbirinden az da olsa farklı olduğu, hız profillerinin su yüzüne yakın bölgelerde (türbülanslı dış bölgede) birbiri ile olan uyumun arttığı görülmektedir. Ayrıca, bu kesitler dışında ele alınan kesitlerde ( $x=90,105,120,140$, $160,180,200$ ve $220 \mathrm{~cm}$ ) sayısal bulguların deneysel ölçümlere kanal başlangıç bölgesinde ele alınan kesitlere göre daha çok yakınsadığı görülmektedir. Çizelge 2'de verilen OKH ve OMGH de değerlerinden elde edilen sonuçlar ile hız profillerinin grafikleri arasında paralellik olduğu sonucuna ulaşılmıştır.

\subsection{Deneysel ve Hesaplanan Su Yüzü Profilleri}

Tablo 4 'te farklı türbülans modelleri kullanılarak elde edilen su yüzü profillerine ait $\mathrm{OKH}$ ve OMGH değerleri verilmiştir. Tablodaki değerlerden RNG türbülans modeli ile elde edilen su yüzü profilinin kullanılan diğer türbülans modellerine göre deneysel ölçümlere daha fazla yakınsadığı görülmektedir. Deneysel ve farklı türbülans modelleri kullanılarak elde edilen su yüzü profillerinin karşılaştırılması Şekil 5'de verilmiştir. Şekilden de görüldüğü gibi SKE, RKE, RNG, MKW ve SST türbülans modelleri ile elde edilen su yüzü profilleri arasında büyük bir fark bulunmamaktadır. $\mathrm{Bu}$ çalışmada niceliksel karşılaştırma kriteri olarak kullanılan ve Çizelge 3'de verilen OKH ve OMGH değerlerine göre su yüzü tahmininde en başarılı model akım hız alanın da belirlenmesinde olduğu gibi RNG türbülans modelidir.

\subsection{Türbülans Kinetik Enerji Topolojisi}

Şekil 6'da, RNG modeli kullanılarak elde edilen türbülans kinetik enerjisinin kanal boyunca değişimi verilmiştir. Şekilden, türbülans kinetik 

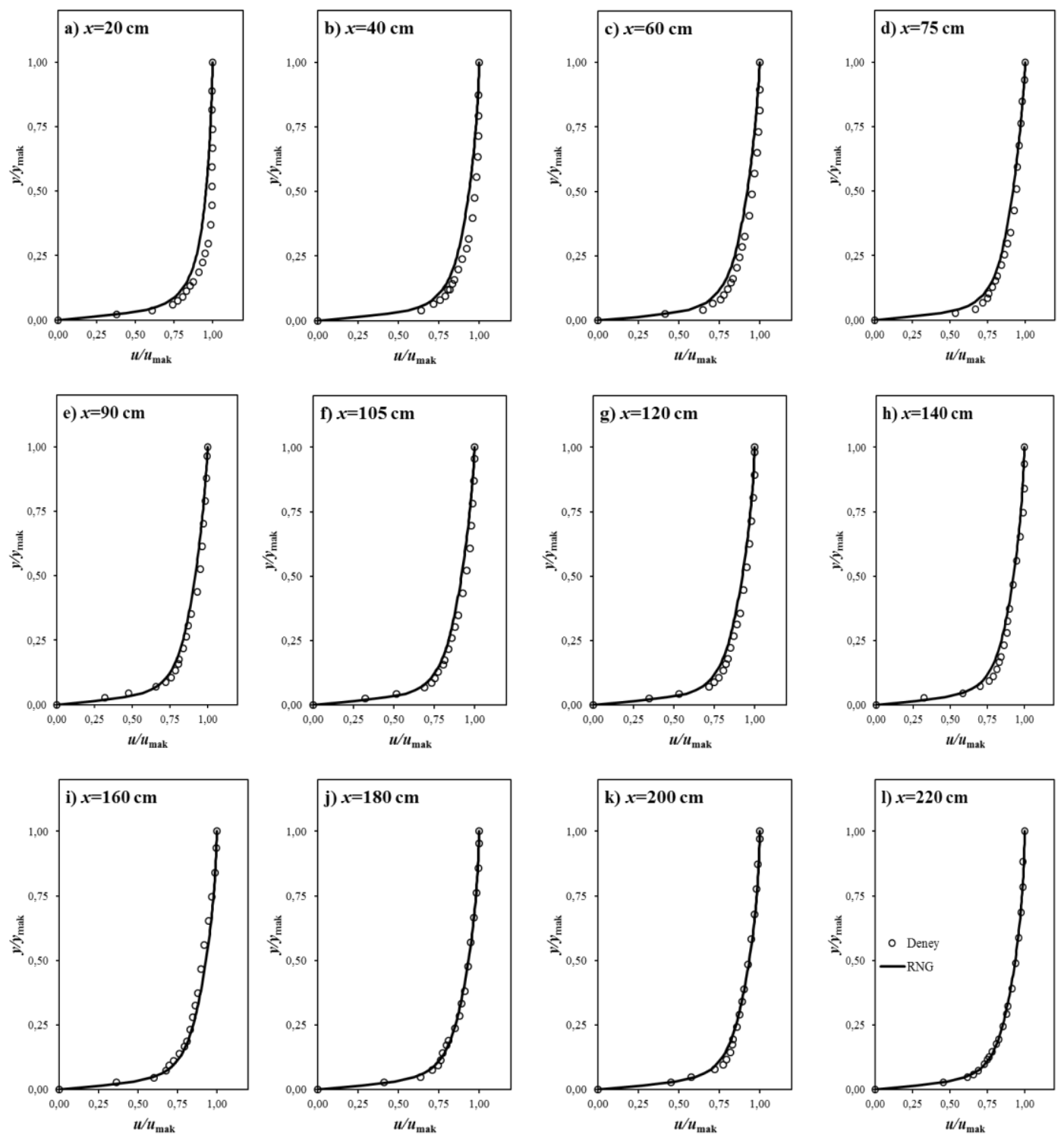

Şekil 4. Kanal boyunca farklı kesitlerde deneysel ve RNG modeli ile hesaplanan boyutsuz hız profilleri

Çizelge 3. Farklı türbülans modelleri ile hesaplanan su yüzü profilleri için $\mathrm{OKH}\left(\mathrm{mm}^{2}\right)$ ve $\mathrm{OMGH}$ $(\%)$ değerleri

\begin{tabular}{|c|c|c|c|c|c|c|c|c|c|}
\hline \multicolumn{2}{|c|}{ SKE } & \multicolumn{2}{c|}{ RKE } & \multicolumn{2}{c|}{ RNG } & \multicolumn{2}{c|}{ SKW } & \multicolumn{2}{c|}{ SST } \\
\hline OKH & OMGH & OKH & OMGH & OKH & OMGH & OKH & OMGH & OKH & OMGH \\
\hline 0,211 & 3,210 & 0,199 & 3,069 & 0,194 & 2,914 & 0,449 & 5,680 & 0,409 & 5,273 \\
\hline
\end{tabular}



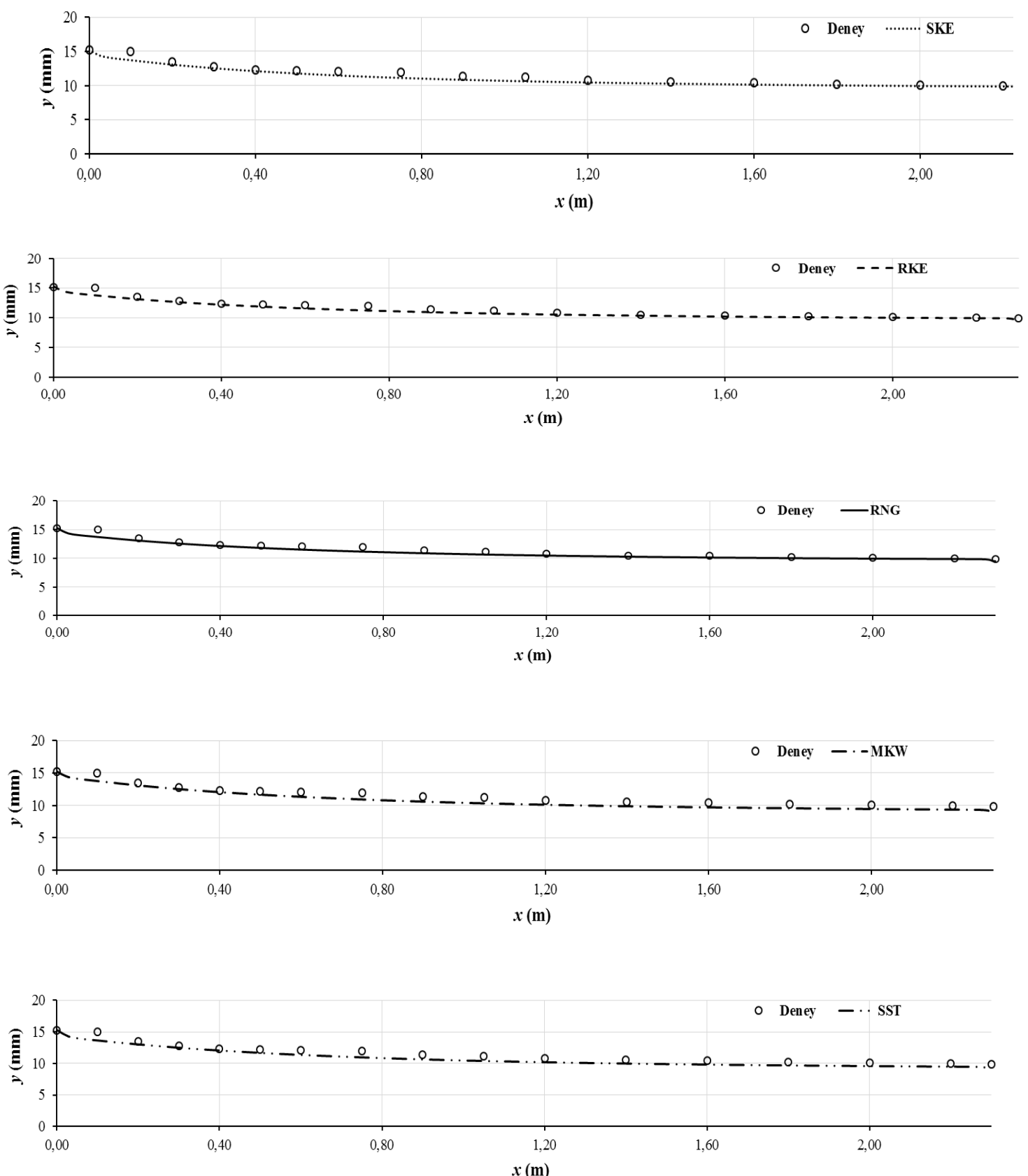

Şekil 5. Deneysel ve farklı türbülans modelleri ile hesaplanan su yüzü profilleri 


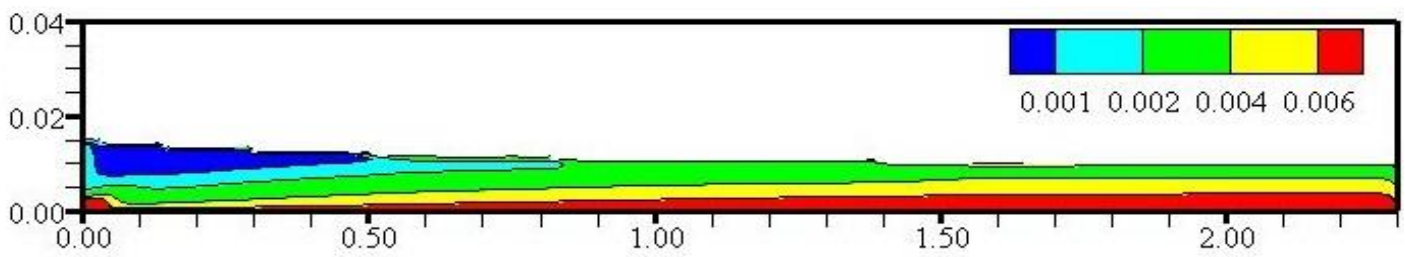

Şekil 6. RNG türbülans modeli ile hesaplanan türbülans kinetik enerji

enerjisinin en büyük değerinin kanal tabanına yakın bölgede oluştuğu görülmektedir. Kanal tabanından su yüzüne doğru türbülans kinetik enerji değeri gittikçe azalmakta ve en düşük 0,001 $\mathrm{m}^{2} / \mathrm{sn}^{2}$ değeri giriş kesitine yakın bölgede oluşmaktadır. Kanal başlangıç noktasından kanal sonuna doğru, akım hızının artması ile birlikte, tabanda oluşan maksimum türbülans kinetik enerji değerinin kalınlığının arttığı görülmektedir.

\section{SONUC}

Eğimli açık kanal akımın sayısal modellenmesinde akımı idare eden denklemler, sonlu hacimler yöntemine dayalı ANSYS-Fluent paket programı kullanılarak çözülmüştür. Sayısal modellemelerde SKE, RNG, RKE, MKW ve SST türbülans modelleri kullanılmış, serbest su yüzünün profili VOF yöntemi ile belirlenmiştir. Hesaplama ağ yapısının, sayısal bulgular üzerindeki etkisini incelemek üzere, Ağ Yakınsama İndeksi (GCI) ölçüt olarak kullanılmış ve ağ yoğunluğuna bağlı hesaplama hatasının \% 2'nin altında kaldığı görülmüştür. Sayısal modellemelerden hesaplanan hız ve su yüzü profillerinin deneysel ölçümler ile karşılaştırılmasından, SKE, RKE ve RNG türbülans modeli ile elde edilen sayısal tahminlerinin birbirine yakın olduğu ve bu çalışmada kullanılan diğer türbülans modeli tahminlerine göre deneysel sonuçlara daha fazla yakınsadığı görülmüştür. Bunun yanı sıra, bu üç model arasından da RNG türbülans modelinin en başarılı model olduğu belirlenmiştir. Sonuç olarak, RNG türbülans modeli, bu tür akım durumlarında diğer türbülans modellerine göre daha başarılı tahminde bulunmuş ve bu tür akımların sayısal modellenmesinde başarılı bir şekilde kullanılabileceği görülmüştür.

\section{TEŞEKKÜR}

$\mathrm{Bu}$ çalışma 14110 nolu proje ile Harran Üniversitesi, Bilimsel Araştırma Projeleri Komisyonu (HÜBAK) tarafından desteklenmiştir, teşekkür ederiz.

\section{KAYNAKLAR}

1. İspir, M.A., Kırkgöz, M.S., Gümüş, V., 2014. Yavaş Değişen Kritik-Altı Açık Kanal Akımının k- $\varepsilon$ Türbülans Kapatma Modelleri ile Sayısal Hesabı. Çukurova Üniversitesi Mühendislik Mimarlık Fakültesi Dergisi. 29(1): 145-155.

2. Şimşek, O., Aköz, M.S., Gümüş, V., 2011. Eğrisel Geniş Başlıklı Savak Üzerinden Geçen Açık Kanal Akımının Deneysel ve Teorik Analizi. Çukurova Üniversitesi Mühendislik Mimarlık Fakültesi Dergisi. 26(2): 45-53.

3. Kırkgoz, M.S., Aköz, M.S., Öner, A.A., 2008. Experimental and Theoretical Analyses of TwoDimensional Flows Upstream of Broad-Crested Weirs. Canadian Journal of Civil Engineering. 35(9): 975-986.

4. Öner, A.A., Aköz, M.S., Kırkgoz, M.S., Gümüş, V., 2012. Experimental Validation of Volume of Fluid Method for a Sluice Gate Flow. Advances in Mechanical Engineering. 2012: 10.

5. Gümüş, V., Aköz, M.S. ve Kırkgöz, M.S., 2013. Experimental and Numerical Modeling of Submerged Hydraulic Jump Downstream of a Sluice Gate. Teknik Dergi. 24(2): 6379-6397.

6. Ramamurthy, A.S., Qu, J.Y., Vo, D., 2006. VOF Model for Simulation of a Free Overfall in Trapezoidal Channels. Journal of Irrigation and Drainage Engineering-Asce. 132(4): 425-428. 
7. Aydin, M.C., 2012. CFD Simulation of FreeSurface Flow over Triangular Labyrinth Side Weir. Advances in Engineering Software. 45(1): 159-166.

8. Haun, S., Olsen, N.R.B., Feurich, R., 2011. Numerical Modeling of Flow over Trapezoidal Broad-Crested Weir. Engineering Applications of Computational Fluid Mechanics. 5(3): 397-405.

9. Kırkgöz, M.S., Aköz, M.S., Öner, A.A., 2008. Experimental and Theoretical Analyses of Two-Dimensional Flows Upstream of Broad-Crested Weirs. Canadian Journal of Civil Engineering. 35(9): 975-986.

10. Öner, A.A., Aköz, M.S., Kırkgoz, M.S., Gümüş, V., 2012. Experimental Validation of Volume of Fluid Method for a Sluice Gate Flow. Advances in Mechanical Engineering.

11. Kırkgöz, M.S., Aköz, M.S. ve Öner, A.A., 2009. Numerical Modeling of Flow over a Chute Spillway. Journal of Hydraulic Research. 47(6): 790-797.

12. Launder, B.E., Spalding, D.B., 1972. Lectures in Mathematical Models of Turbulence. New York: Academic Press.

13. Yakhot, V., Orszag, S.A., Thangam, S., Gatski, T.B.,, C.G., 1992. Development of Turbulence Models for Shear Flows by a Double Expansion Technique. Physics of Fluids a-Fluid Dynamics. 4(7): 1510-1520.

14. Shih, T.-H., Liou, W.W., Shabbir, A., Yang, Z., Zhu, J., 1995. A New k-€ Eddy Viscosity Model for High Reynolds Number Turbulent Flows. Computers \& Fluids. 24(3): 227-238.

15. Wilcox, D.C., 2006. Turbulence Modeling For CFD (Third Edition). California: DCW Industries, Inc.

16. Menter, F.R., 1994. 2-Equation EddyViscosity Turbulence Models for Engineering Applications. Aiaa Journal. 32(8): 15981605.

17. Hirt, C.W., Nichols, B.D., 1981. Volume of Fluid (VOF) Method for the Dynamics of Free Boundaries. Journal of Computational Physics. 39(1): 201-225.

18. ANSYS. 2012. FLUENT Theory Guide. USA: ANSYS Inc.
19. Chen, H.C., Patel, V.C., 1988. Near-Wall Turbulence Models for Complex Flows Including Separation. Aiaa Journal. 26(6): 641-648.

20. Roache, P.J., 1998. Verification of Codes and Calculations. Aiaa Journal. 36(5): 696-702.

21. Celik, I.B., Ghia, U., Roache, P.J. ve Freitas, C.J., 2008. Procedure for Estimation and Reporting of Uncertainty Due to Discretization in CFD applications. Journal of Fluids Engineering-Transactions of the Asme. 130(7). 
